\title{
Psycho-Spiritual Strategies in Treating Addiction Patients: Experience at Al-Amal Hospital, Saudi Arabia
}

\author{
Mohamed Omar Salem, MBChB, DPM, BCPsych, FRCPsych; ${ }^{1}$ \\ Mohamad Medhat Ali, MBChB, DPM;2 \\ 'Department of Psychiatry, Faculty of Medicine \\ United Arab Emirates University \\ Al-Ain, United Arab Emirates \\ ${ }^{2}$ Sharja Rehabilitation Centre \\ United Arab Emirates
}

\begin{abstract}
Addictive behavior generally, and addiction to alcohol and drugs in particular, are among the most challenging facets of contemporary psychiatry. In addition to the high comorbidity associated with various psychiatric disorders, the addict also has psychological, social, and spiritual concerns. Thus, a holistic approach to the problem is more than justified. Psychologists and psychiatrists for many decades have neglected the spiritual dimension in particular. The multidisciplinary team at the Al-Amal Hospital Project in Saudi Arabia adopted the holistic bio-psycho-socio-spiritual model and has found success in dealing with this problem. On admission, the patient signs a treatment contract and reports to the B Ward for biological, psychological, social, and spiritual assessment. After assessment, the team designs a management plan for each patient to be carried out at the rehabilitation unit. The patient usually stays in this unit for 3-6 weeks before discharge from the hospital. After discharge, the patient is followed up as an outpatient by the continued care unit.

This paper primarily highlights the details of the spiritual aspects of this intervention, then discusses the possible mechanisms involved, cognitive restructuring, religious-induced positive affective states, and behavior modification strategies.
\end{abstract}

Keywords: Addiction rehabilitation, Islam.

Introduction

ddictive behavior in general and addiction to
alcohol and drugs in particular are among the
most difficult challenges of contemporary psy-

Correspondence should be directed to

Mohamed Omar Salem, MBChB, DPM, BCPsych, FRCPsych

Department of Psychiatry, Faculty of Medicine

United Arab Emirates University

PO Box 17666

Al-Ain, United Arab Emirates chiatry. In addition to the high comorbidity of various psychiatric problems, such as personality disorders, depression, self-harm, and psychosis, the addict patient also has psychological, social, and spiritual concerns. ${ }^{1}$ Hence, a holistic-integrated approach to the problem is more than justified. Alcoholics Anonymous (AA) acknowledges this holistic approach to the problem of addiction. In its documents, it emphasizes that addiction affects the body, mind, and spirit. ${ }^{2}$ Psychologists and psychiatrists have generally neglected the spiritual dimension in managing psychiatric patients for many decades. ${ }^{3}$ 


\section{Al-Amal Hospital Project in Saudi Arabia}

The Al-Amal Hospital Project consists of four specialized psychiatric hospitals for treatment of alcohol and drug abuse. They are located in Jeddah, Riyadh, Buraida, and Al-Dammam to serve the major population centers. This paper will focus on our experience at Al-Dammam Hospital, where the first author was the consultant psychiatrist in charge of the short-term rehabilitation unit, and the second author was working as a psychiatrist in the detoxification/assessment unit. ${ }^{4}$

\section{Al-Amal Hospital in Dammam}

Al-Amal Hospital in Damman consists of 280 beds, with 320 clinicians and other staff members. The work was based on a multidisciplinary team approach, executing a comprehensive treatment program, where the holistic bio-psycho-socio-spiritual model was successfully adopted. The program was implemented through the three hospital units: the assessment-detoxification, short-term rehabilitation, and aftercare units. The patients' population incorporated mainly poly-drug abusers (including opiates), with a minority of alcoholics (about 10\%). The average number of admissions to the hospital was about 1850 male patients per year. The relapse rate over 2 years was $25 \% .^{4}$

The Al-Amal project does not serve female addicts. Drug abuse among women in Saudi Arabia is extremely rare. Such patients would be admitted to the female psychiatric ward at the local general psychiatric hospital, mainly for detoxification and simple supportive interventions.

\section{Admission Contract}

On admission, patients sign a treatment contract agreeing to stay for a minimum of 1 month to get the treatment package. During this month, patients have no power to discharge themselves from the hospital, and the patients are educated about the philosophy behind this policy. Craving for the abused substance usually peaks within a short period after admission to the hospital. This renders patients weak and possibly unable to resist the temptation to leave the program in order to gain access to the drug. Therefore, patients agree to stay in the hospital, even if they later change their minds. Patients are not allowed to leave without written permission from the treating doctor; which is usually allowed at the end of the 1-month period.

\section{Assessment/Detoxification Unit}

During the phase of detoxification in Ward B, the multidisciplinary team will assess the patient in the four areas (bio-psycho-socio-spiritual). This team includes psychiatrists, psychologists, social workers, religious leaders, chemical dependency counselors (ex-addicts), nurses, and occupational and industrial therapists. During the assessment phase, the team will design a provisional management plan for each patient to be carried out in the short-term rehabilitation unit.

\section{Short-term Rehabilitation Unit}

This phase is carried out in two wards (C and D) where the patient usually stays for 3-6 weeks before being discharged from the hospital. In this unit, further evaluation is carried out to arrive at a final diagnosis, considering the frequently associated comorbidity. Then, an individualized treatment plan involving the entire multidisciplinary team will be refined and implemented through a program of individual and group activities. The treatment program adopted is a combination of both the psychiatrically oriented and the AA-oriented rehabilitation models, with some modification to fit into the local Islamic culture.

The unit environment was designed to provide a therapeutic milieu and organized to provide a structured environment, based on behavioral lines. The philosophy behind this approach is that the addicts' lifestyles are often chaotic, with irregular eating and sleeping habits. ${ }^{5}$ Hence, the program was designed to provide a consistent structure to help the recovering patients adjust to a regular lifestyle. For example, patients coming late might lose some program privileges.

\section{After Care Unit}

After discharge, the patients attend this unit as outpatients, with the same model approach. It aims at relapse prevention by helping patients develop viable and effective alternatives to their addictive behavior. Techniques used include problem-solving training, building self-esteem and confidence to help restore the social role, and maintaining the strategies already taught to cope with craving for the misused drug. The client's religious community provides 
community support and social networking as an extra therapy resource.

\section{Auditing}

A quality assurance officer with an assistant regularly check nine quality indicators covering all clinical areas, including spirituality. Considering the biopsycho-socio-spiritual model, we had four areas to be addressed, namely the medical, psychological, social, and spiritual domains. Each domain is evaluated in both assessment and management. The ninth indicator is the adherence to the detoxification protocol.

In this paper we shall focus mainly on the details of the psycho-spiritual aspect of the program.

\section{The Psycho-Spiritual Program}

It included a variety of individual and group interventions.

I. The individual interventions included:

A. Spiritual Guidance

This service is carried out by the religious leader (imam), who is a member of the multidisciplinary team. His religious counseling aims at faith revival and helping the addict to incorporate both the cognitive aspect (beliefs) and the behavioral component (practices) into his daily life. Spiritual practices are focused activities aimed at fostering the spiritual qualities that can result in a balanced and disciplined lifestyle. ${ }^{6}$ This includes prayer, contemplation and meditation, fasting, forgiveness, and caring for others. Cox proposed to have a religious counselor as a member of the multidisciplinary team. ${ }^{7}$

In the Islamic world it is widely known that alcohol and drug misuse are prohibited on religious grounds (harām, impermissible), hence the religious program is centered mainly on faith revival, with particular attention to areas of repentance, God's forgiveness and mercy, and making the afterlife the main concern. Night prayer was particularly helpful for patients with insomnia as part of the residual withdrawal syndrome. Monthly trips to the Holy Mosque in
Makkah (for 'umra, the lesser pilgrimage) were part of the religious program of Al Amal project.

B. Self-Help

1. Religious bibliotherapy: recommending some religious or spiritual literature: e.g.: sacred texts, books, articles, tapes, or videos.

2. Spiritual meditation and prayer.

3. Religious journal writing: keeping a diary about areas of satisfaction, spiritual struggles, insights and spiritual experiences e.g. answered prayers, significant religious experiences, dreams that come true, etc.

4. Scripture memorization: Selected verses of the Holy Qur'an and prayers to help as a means of coping in difficult times or when under stress. Also, it can be used for motivation.

C. Acupuncture and Relaxation Sessions

The role of acupuncture in treating addiction has been widely acknowledged. The main benefit of this nonpharmacological technique is to reduce body pains and the anxieties of the withdrawal syndrome. ${ }^{8}$ These sessions consisted of daily morning auricular acupuncture application while practicing relaxation techniques. When deep relaxation is taught and mastered, guided imagery and autosuggestion techniques are introduced with direct reference to spiritual concepts such as total psychological and spiritual surrender to God, relying on Him to get the power to overcome weakness for substance abuse, etc.

D. Individual Eclectic Psychotherapy

Psychological treatment is usually described according to its school. Thus, there are the analytical, humanistic, existential, supportive, behavioral, cognitive, dynamic, and interpersonal approaches of psychotherapy. Eclectic psychotherapy is the integrative psychotherapeutic approach specifically designed to suit the different needs of the individual patient. Cognitive behavior therapy (CBT) is one of the modern psychological treatments. 
It is a combination of behavioral and cognitive therapy in one modality. One version of this treatment is CBT with religious content, which is the most appropriate intervention for Muslim patients, as Muslim communities are predominately religiously committed societies. Such clinical psychological work on the individualized patient would generally start by highlighting his strengths and weaknesses. It would then aim at building his self confidence and self-esteem on healthy grounds, developing his coping strategies and providing him with the necessary skills to polish his problemsolving abilities.

II. Group Interventions

These are daily group meetings designed to make use of the therapeutic effect of group dynamics to enhance the treatment program. They consist of the community meeting, the group psychotherapy session, and the recovery group meeting. In addition, there are also a variety of group activities.

A. Community Meeting

All patients and staff of a ward attend a meeting at the beginning of each day to identify and resolve patients' community issues, make plans for activities, and share announcements. It starts by one patient reciting a few verses of the Glorious Qur'an, and the group comments and reflects on their meanings. Then new patients and staff are introduced. Other issues are discussed as they emerge.

B. Recovery Groups

This group is facilitated by the drug dependency counselor using a multicomponent treatment package program based on the Islamic version of the 12step program of AA. Technically, it is a CBT approach with religious content. The 12 steps have been modified to conform to Islamic teachings (Table 1).

C. Religious group activities

All patients and Muslim staff pray together in the hospital mosque. The religious guidance leader delivers a regular
Table 1. The Islamic version of the 12 Steps of Alcoholics Anonymous.

1. We admit that we are powerless over alcohol and that our lives have become unmanageable.

2. We have come to believe that Allah alle can restore us to sanity.

3. We have made a decision to turn our wills and our lives over to the care of Allah dili.

4. We have made a searching and fearless moral inventory of ourselves in the light of the Islamic doctrines (s hari'a).

5. We admit to Allah and to ourselves the exact nature of our wrongs.

6. We are entirely ready to pray to Allah to remove all these defects of character.

7. We have humbly asked Him to remove our shortcomings.

8. We have made a list of all persons we have harmed, and we have become willing to make amends to all.

9. We have made direct amends to such people wherever possible, except when to do so would injure them or others.

10. We continue to take personal inventory, and, when we do wrong, we promptly admit it.

11. We seek through prayer and other religious commitments and activities to improve our conscious contact with Allah, praying only for knowledge of His will for us and the power to carry that out.

12. We have had a spiritual awakening as the result of these steps. We try to carry this message to alcoholics and practice these principles in all our affairs.

short speech following prayers aiming at faith revival. During the holy month of Ramadan, fasting is observed, and the spiritual activities are intensified, including the special night prayer (qiyām) of the month.

\section{Discussion}

The psycho-spiritual program adopted in this model is an excellent example of the interface between religion as a cultural construct and psychiatric practice. Apparently, spirituality as a strong motivating force has been a topic of increasing interest to clinicians and researchers interested in addiction. ${ }^{9}$ Over the last few decades an increasing number of well-designed studies have been published in 
this field, and most of them supported a positive correlation with mental health. ${ }^{10}$

The positive association was evident in the areas of prevention, coping with problems, and maintaining recovery. Almost every study that has examined the relationship between religion and alcohol and substance abuse has found lower rates of abuse among religious populations. ${ }^{11-4}$

Proposed mechanisms to achieve the healing changes are numerous. One of these is cognitive restructuring using the patient's religious frame of reference to enhance his spiritual-existential worldview. Religion promotes positive cognitions like hope and optimism with their strong positive effects. The positive affective states of the spiritual experience would turn the brain pleasure center to new cues of pleasure, hence rechanneling and redirecting the pleasure-reward response to the new religious experience. ${ }^{15}$

Also, the program includes behavioral and social elements to restore a healthier lifestyle. One of the major causes of relapse of drug abusers is unhealthy social networks. Rehabilitation is never complete without substitution of previous morbid social networks with healthy ones. This goal is very difficult to achieve outside religious communities who share common standards for right (haläl, permissible) and wrong (harām) behaviors. Drug use is certainly one of the most forbidden areas. Through the mosquebased religious activities: praying, Qur'an circles, retreats, and charity works, new social networking can be established with people of similar interests, and these enhance positive personality transformation. This newly established networking can also be a major source of social support, which can maintain the healthy lifestyle of the recovering addict. ${ }^{16}$

As the majority of the Saudi community is Muslim, it was of particular interest to incorporate Islamic teachings into these therapeutic techniques as demonstrated in the psycho-spiritual program detailed above.

The outcome of this program seemed to be successful as indicated by various parameters. The average length of stay for patients was 35.8 days, which exceeded slightly the targeted minimum stay of 1 month. Dropouts were only $2.8 \%$, and the relapse rate (over 2 years) was $25 \%{ }^{4}$

In conclusion, this innovative program serves, with its psycho-spiritual component, as a useful model of substance abuse rehabilitation program for Muslim communities.

\section{References}

1. Gossop M. Addiction and after. Br J Psychiatry. 1988;152:307-9.

2. Alcoholics Anonymous World Services. How It Works. In: Alcoholics Anonymous: the story of how many thousands of men and women have recovered from alcoholism. 3rd ed. New York: Alcoholics Anonymous World Services; 1976. p. 58-71.

3. Dein S. Religion and mental health. British Medical Anthropology Review. 1996;3:40-9.

4. Abdel-Mawgood M, Fateem L, Al-Sharif AI. Development of a comprehensive treatment program for chemical dependency at Al Amal Hospital, Dammam. J of Subst Abuse Treat. 1995;12:369-76.

5. Mann GA. Recovery of reality: overcoming chemical dependency. San Francisco, CA: Harper and Row; 1979.

6. Ali OM, Milstein G, Marzuk P. The Imam's role in meeting the counseling needs of Muslim communities in the United States. Psychiatr Serv. 2005;56:202-5.

7. Cox JL. Psychiatry and religion: a general psychiatrist's perspective. In: Psychiatry and religion. Bhugra D, editor. London: Routledge; 1996.

8. Smith M, Khan I. An acupuncture programme for the treatment of drug-addicted persons. Bull Narc. 1988;40:35-41.

9. Cook CC. Addiction and spirituality. Addiction. 2004;99:539-51.

10. Koenig HG. Is Religion Good for Your Health? New York: The Haworth Press; 1997.

11. Parfrey PS. The effect of religious factors on intoxication use. Scand J Soc Med. 1976;3:135-40.

12. Larson DB, Wilson WP. Religious life of alcoholics. South Med J. 1980;73:723-27.

13. Khavari KA, Harmon TM. The relationship between the degree of professed religious belief and the use of drugs. International Journal of the Addictions. 1982;17:847-57.

14. Koenig HG, George LK, Meador KG, et al. Religious practices and alcoholism in a southern adult population. Hosp Community Psychiatry. 1994;45:225-31.

15. Pargament KI. The psychology of religion and coping. New York: The Guilford Press; 1997.

16. Krause N. Stress, religiosity, and abstinence from alcohol. Psychol Aging. 1991;6:134-44. 